\title{
Coronavirus SARS-CoV2, Beyond the Damage: Thinking of Humanity in the Grip of Natural Selection, and its Management by Evolutionary Medicine
}

\section{Mbangmou Romuald Stone*, Nkuitchoua Ngatcha Edwige Carole and Leonard Nguimfack}

Department of Psychology, University of Yaounde 1, Cameroon

*Corresponding Author: Mbangmou Romuald Stone, Department of Psychology, University of Yaounde 1, Cameroon.

DOI: 10.31080/ASMS.2020.04.0697
Received: April 05, 2020

Published: July 28, 2020

(C) All rights are reserved by Mbangmou

Romuald Stone.

\begin{abstract}
In this period of global health crisis caused by the SARS-CoV2/Covid-19 coronavirus pandemic, it is necessary to rethink all of humanity. This revision of human posture must be made in relation to the priority choice of saving human lives on the one hand or saving the human species on the other. Even if most of the peoples of the earth seem inclined to preserve human lives, it is now clear that for the SARS-CoV2 coronavirus, the survival of the human species is its primary mission. This work of reflection analyzes the impact of the passage of Covid-19 on the humanity of tomorrow, while proposing some medical techniques, stemming from evolutionary theories, which can make it possible to take care of the sick, insofar as it is turns out to be important.
\end{abstract}

Keywords: SARS-CoV2 Coronavirus; Natural Selection; Evolutionary Medicine; Conventional Medicine; Natural Defence Mechanisms

\section{Introduction}

Covid-19, understood by that corona virus disease 2019 , is the disease caused by the Coronavirus SARS-CoV2. First called 2019nCov2 before being renamed SARS-CoV2 (Severe Acute Respiratory Syndrome-Corona Virus second strain), which is an emerging virus whose reservoir animal is the bat [1] and the species intermediary would be the pangolin "We can think that human contamination occurred during the manipulation of these mammals whose scales are used in the traditional Chinese pharmacopoeia and whose flesh we consume" (Berche, quoted by Santé magazine). Apart from animal 1 (reservoir) -animal 2 (intermediate) transmission - Man, the SARS-CoV2 coronavirus, like SARS-CoV and MERS-CoV, is also transmitted from Man to Man through direct physical contact and indirect through infected surfaces. Barrier measures are the best way to stop the spread of infection (wash your hands frequently with soap or hydroalcoholic gel, sneeze and cough in your elbow, use single-use tissues, do not shake hands, do not kiss to say hello, avoid touching your face during the day).

The main symptoms of this disease are: sore throat, cough, fever, and difficulty breathing for severe cases. Some patients may experience aches, headache, tightness or shortness of breath and, in rare cases, sudden loss of smell and loss of taste [2]. Its average incubation time is 5 days, with a confidence interval between 2 and 12 days. However, some people have an asymptomatic form of the virus because they carry the virus, without showing symptoms, but can transmit it to others. A biological test (PCR, polymerization by chain reaction) by nasopharyngeal sampling confirms an infection with the SARS-CoV2 Coronavirus. No vaccine to date, but it appears to be in production. The treatment aims to relieve symptoms, (antipyretic), however, the prescription of hydroxychloroquine has just been authorized in several countries (United States, Morocco, 
Coronavirus SARS-CoV2, Beyond the Damage: Thinking of Humanity in the Grip of Natural Selection, and its Management by Evolutionary Medicine

Senegal, Cameroon France, etc.). Other molecules are in European clinical trial called "Discovery". The disease is mild in $80 \%$ of cases, severe in around $15 \%$, and critical in $5 \%$. Those most at risk are those with preexisting chronic diseases (hypertension, cardiovascular disease, diabetes, liver disease, respiratory diseases like asthma...) are more likely to develop severe forms, as are the elderly (over 70) and immunocompromised. Researchers estimate the overall mortality rate of the virus between 2 to $4 \%$, with disparities depending on the country. Statistics show that as of April 1, 2020, more than one million people have been infected, more than 54 thousand deaths, 220 thousand cured, 38 thousand critical cases, with approximately 250 thousand cases of infections recorded in the United States. United, which has become the main focus of the pandemic. This work allows us to take an evolutionary look the Covid-19 pandemic, starting by presenting evolutionary medicine, then its reading and its application to the Covid-19 pandemic, and ending by highlighting the positive aspects of the passage from one such phenomenon, always from the evolutionary point of view.

Conventional biomedical medicine and evolutionary medicine

Faced with a bacterial or viral threat, conventional medicine poses the question of how. According to McGuire, Marks, Nesse and Troisi [3], this questioning spans two axes, namely, the etiological axis which questions the cause and the pathogenic axis which questions its pathophysiological mechanism. We can, alongside these two axes, add the therapeutic axis which poses the question "how to break its pathophysiological process? ". Unlike this conventional medicine, evolutionary medicine, for its part, questions the Why, in relation to the onset of the disease and the explanation of its symptoms in order to produce a treatment [3]. The approach of evolutionary medicine wonders why these symptoms exist. What are they used for or what is their function? The relationship between the parasite and its host is viewed from the evolutionary point of view as a struggle for survival and domination. It is a struggle between two equal species, the only difference of which is the means used by each protagonist to fight the defenses of the other. In other words, the parasite and its host are two equal organisms, each of which only asks to survive, using the means that have been made available to it by nature. Unlike conventional medicine, which considers all symptoms as pathological [4], evolutionary medicine considers certain symptoms as adaptive, as defense mechanisms [3]. For example, the release by the host of the endogenous leukocyte mediator increases its body temperature and decreases the amount of iron in the blood by $80 \%$, to store it in the liver [3]. The decrease in iron reduces the speed of propagation and multiplication of the bacteria since it needs iron to ensure this propagation and this multiplication, and it is well known that the rise in temperature kills several bacteria and viruses. From this point of view, fever and anemia are adaptive mechanisms put in place by the host organism. But then, in certain cases, the host organism can: - with regard to the quantity of iron, - either create a fatal kiss by loss of control of this process of iron reduction, either have control but, do not resist the level of drop necessary to hope that kill all bacteria; with regard to temperature, the host organism can: -or produce a high temperature level which can cause damage to other vital organs and the death of the host ensues, -or losing control of this hyperthermic process initially started to fight the parasite, which can also lead to the death of the host. Faced with this situation of bacterial infection, unlike the biomedicine doctor who will prescribe an antipyretic to decrease the temperature and a ferric potion to increase the value of iron in the blood, the evolutionary approach doctor asks himself the question of how to do it so that the host's body can withstand high temperature and a lower iron level? This in order to potentiate the defense mechanisms already naturally put in place by the body, and not to combat them as does the conventional approach; or how do you prevent the parasite from being pathogenic to its host? This raises the question of the vaccine, which is a rather evolutionary technique, even if it remains artificial.

Application of evolutionary medicine to the management of disorders linked to SARS-CoV2 coronavirus infection

The current protocol for managing Covid-19 is the combination of chloroquine, a former antimalarial drug that has been on the market since 1939 and azithromycin, a macrolide antibiotic from the azalides group, derived from erythromycin.

In an evolutionary medical approach, after having identified the cause and the symptoms of the Covid-19 pandemic, we should seek to know, outside of any political debate, why is it present, why these symptoms and not others? As the host organism is the most knowledgeable about the virus, it is best placed to develop effective defense mechanisms. These defense mechanisms are in the form of symptoms, and these symptoms should point towards care and should be respected. 
Coronavirus SARS-CoV2, Beyond the Damage: Thinking of Humanity in the Grip of Natural Selection, and its Management by Evolutionary Medicine

\section{Sore throat}

This is the consequence of the inflammatory reaction put in place by the surrounding cells which, by releasing histamine, attracts greater blood flow to the infected area. This additional blood supply simultaneously involves the increase of antibodies in this attacked area, which allows the body to better fight the infection. Physiologically speaking, we know that these types of inflammation produce feelings of heat. It's what you feel after hitting your toe on a stone. From an evolutionary point of view, this inflammation process should be potentiated by taking hot drinks. Moreover, several information not scientifically proven run in the populations that the regular catch of the hot drinks would contribute to eliminate the viruses when they are still at the level of the throat, which corresponds with this aspect of the evolutionary reading of the catch in symptomatic load of Covid-19.

\section{Cough and respiratory failure}

According to Quevauvilliers, Somogyi and Fingerhut (P: 933) [5], it is "a sudden, noisy, more or less repeated expulsion of air contained in the lungs, in order to expel any irritant substance from its respiratory tract". It is a natural expectorant process, which expels air, which helps get rid of irritation in the throat and upper pulmonary tract. In the case of Covid-19, coughing becomes an effective way to eliminate a good part of the virus in the body, at the same time, allows to exercise and keep the lungs active, to better resist the constraints imposed by SARS- CoV2. The evolutionary medical approach would suggest to patients and non-affected people, to repeat this abrupt and noisy expulsion of air from the respiratory tract regularly, in order to optimize the body's natural defenses, by providing this a higher amount of oxygen, and increasing the level of flexibility of the cells and pulmonary ways. The ensuing breathing difficulties during the complications of Covid-19 are only the expression of the failure of this defense mechanism, a failure which would be facilitated by the comorbidity and risk factors, as described by observations in care settings, and by statistical studies, namely cardiovascular disease, high blood pressure, diabetes, smoking, cancer [6,7] and obesity [8].

\section{Fever}

Fever is a special form of increased body temperature, also called hyperthermia, produced by the body itself in response to an infectious disease process. It is the most powerful antibacterial weapon developed by the body over millions of years of evolution. The fever developed by the Covid-19 patient's body is an expression of this protective process. Moreover, it has been shown that "the lifespan of certain viruses is reduced by heat and certain viruses" [9]. One study looked at the SARS-CoV2 coronavirus and concluded that an outside temperature between 20 and $30^{\circ} \mathrm{C}$ would reduce the virulence of the virus. Despite the criticisms leveled at this study about the short search duration and the reduced number of subjects in the sample, it is clear that these conclusions remain logical. The evolutionary medical approach in such a situation should seek to potentiate the ambient temperature of virus carriers, active or not, or even advise all populations to stay in a rather warm environment, which would limit both the speed of contagion in populations and the level of aggressiveness of the virus in infected people.

\section{Body aches and headaches}

These symptoms, common to several infectious diseases, are a defense mechanism of the organism aimed at limiting the physical efforts of the subject. This is to put him into compulsory rest. In fact, specialists offer rest which, according to them, contributes to remission without treatment in around $80 \%$ of cases. The body, knowing that it has put in place a process reducing the amount of iron in the blood, knows that this will systematically lead to a decrease in energy production (ATP), which could be a serious problem if the subject continues to exercise energetically as usual. This symptom is comparable to the hibernation that we see in polar bears, which aims to minimize energy costs.

\section{Sudden loss of smell and loss of taste}

New symptoms attributed to Covid-19, ageusia which is the loss of taste, and anosmia which is the loss of smell, are visible symptoms in young adults under 40 years of age [9]. These symptoms are not yet explained by scientific research. Curiously, these two symptoms are not observed in Chinese, but are found in French and Anglo-Saxons, said Jerome Salomon, director general of French Health. This symptomatological discrepancy can be explained according to two hypotheses, all of which are evolutionary. On the one hand, this could be explained by the biophysiological variances that exist between the white race and the yellow race. This hypothesis would highlight a higher adaptive capacity of the yellow race on the white race, as regards the resistance of the olfactory and gustatory systems. On the other hand, this semiological discrepancy could be explained by a mutation of the virus, which offers it the possibilities of better assaulting its host. In the latter case, it is possible that the next Chinese infected, those infected with the new European strain, will also have these symptoms. 
To return to the usefulness of these symptoms, we know that taste and smell regulate our eating behaviors, by telling us about the flavor, quality and danger of the food. Smell plays a particular role in sexual behavior, whether in its practice or in the search and long-term maintenance of the sexual partner [10]. From this point of view, the suppression of smell would aim to reduce the patient's sensitivity to surrounding sexual stimulation, which would in some way limit the speed of social contamination. Swallowing remains one of the factors, perhaps the only factor that would allow viruses to leave the throat for the upper respiratory tract. Avoiding swallowing and reducing it would therefore be an effective way of limiting the spread of viruses in the pulmonary respiratory tract. From this point of view, coughing properly before eating a meal would be less harmful for the patient, since it would have reduced a large number of viruses in his throat, which would reduce the number of viruses that will be transported to these respiratory tracts higher.

Summary of evolutionary techniques and strategies proposed for the management of Covid-19

General population prevention strategies

For an uninfected population

For an uninfected population, the ideal would be to promote: either avoidance behavior by setting up a barrier separating them from populations and individuals potentially sick or carrying the virus, which is not always obvious because, today, globalization has made all populations interdependent; Either confrontational behavior by preparing the organisms of individuals to face the disease, by optimizing the performances of these organisms by a vaccine, or by the practice of preventive sport. In the case of the SARS-CoV2 coronavirus, it is for preventive sport to exercise the organs targeted by the virus, in particular the lungs. Regular inspiration-expiration exercises for those who cannot safely exercise, and strenuous exercise for those without known health problems, which prove that sport can be fatal.

\section{For an infected population}

Populations already infected, we can either implement avoidance behaviors such as barrier gestures (washing hands regularly, social distancing measures, general wearing of masks, consumption of hot and alcoholic drinks, to limit contamination, the respiratory and sports exercises described above to reduce complications in future patients); let the virus do its work, taking no special precautions, except to take care of the seriously ill if necessary. This last measure remains the most appropriate, if we must think of the survival of humanity, and not that of individuals. Remember that the goal of evolution is the survival of the species, not that of individuals. This approach has another advantage, that of being very economical: there are no drugs, masks, or medical equipment to buy. To date, France alone is at around 300 billion euros of funds allocated to the Covid-19 pandemic, the Senegalese government has spent 1000 billion CFA francs, which represents huge expenses for these two countries, not citing than those. In addition, these expenses have little impact on the passage of the Covid-19 because, whatever the effort made by a government, the number of deaths cannot be reduced to more than $20 \%$. In this situation, what is the point of exposing the future of $95 \%$ of healthy or surviving and immune people, to the detriment of the $5 \%$ who present with serious forms whose $3 / 4$ will die whatever we do?

\section{Patient care}

The global approach must be centered on the potentiation of the symptoms, and not on their inhibition as does the current approach. The sick must be kept in warm environments, we must encourage expectoration by natural gestures (cough regularly), absolute rest to potentiate the body's general defenses, prescribe breathing relaxation exercises to limit the risk of distress respiratory, avoid intercourse which consumes a lot of organic energy, ensure a diet centered on the potentiation of antibody activities, but above all, avoid questionable antibiotics because, the risk of resistance and mutation of the virus is much higher in this case. And if there is resistance and or mutation of the virus, it will be a new test for all populations, that is to say a new pandemic, which will surely be able to claim more victims.

\section{SARS-CoV2 coronavirus and natural selection: a test beneficial} to humanity?

\section{General information on the theory of natural selection}

The theory of natural selection considers that the evolution of species is done by random variations from one generation to the next, hereditary variations on which a selection by environmental conditions then operates [11]. According to this Darwinian theory of 1859, the new species would come from genetic errors or mutations. A mutation would be beneficial if it contributes to the improvement of the adaptive mechanisms of the organism, and lethal if it contributes to the decrease in the adaptive efficiency of the organism. Natural selection has two components, namely: 
Coronavirus SARS-CoV2, Beyond the Damage: Thinking of Humanity in the Grip of Natural Selection, and its Management by Evolutionary Medicine

heritable variability (mutation or genetic error) and differential reproduction [3]. Thanks to these mutations, certain individuals find themselves with a higher capacity of adaptation than others, faced with certain situations. We have the case of sickle cell patients who are very exposed to certain cardiovascular diseases but, protected from malaria. The less adapted organisms die, while those which are more adapted survive and multiply. These adaptations involve both the biological and the psychological [3]. The death of less suitable organisms is induced by environmental factors, which can be the climate, the modification of the food chain, diseases, and many others.

\section{SARS-CoV2 targets: A coincidence?}

As mentioned in the introduction, SARS-Cov2 coronavirus causes serious complications and death, more in the elderly (over 60 years). In young people, only people with cardiovascular disease and or chronic disease have complications and death. Healthy young adults, children and infants are spared these complications, and these groups have had almost no death from Covid-19 [12,13]. This finding suggests that SARS-CoV2 methodically selects its victims, who are people it considers unsuitable for life on earth. It may sound offensive to label these vulnerable groups as unsuitable, but that is the reality. Natural evolution is very distinct from scientific evolution. If science had not evolved, many people today who died immediately from the Covid-19 would not have been alive for quite some time. Thanks to scientific and technological progress, these people live and procreate, that is to say transmit genes unfavorable to survival to their descendants. This is the case of type 1 diabetic, hemophiliacs. It may be hard to say, but from an evolutionary point of view, these people have no right to life, let alone procreation. Nature is not aware of the humanist theories and laws established by human societies and organizations. Besides, man is only a tiny element in the universe, like a grain of sand on earth. The coronas SARS-CoV2 comes by there, to sift naturally the human species, like a trader who sifts his corn or bean seeds to rid his goods of bad seeds, in order to ensure that his product will be attractive on the market. market; its action is even better compared to that of a farmer who must rid his seeds of bad seeds, in order to make sure that the harvests will be made up only of good seeds. This is the reality, even if it can be painful for some people to see things interpreted in this way: the covid-19, beyond the damage, guarantees a promising future for humanity, by offering more chances in society to people apt, which will ensure their survival, and guarantee their reproduction. From an evolutionary point of view, the human being should not live more than 60 years, because one becomes a burden for the others, and a brake for the survival of the species. We only have to observe what happens in families with the elderly before their referral to retirement homes. Covid-19 is for humans what antioxidants are for the body: destroying molecules harmful to its proper functioning.

The passage of the SARS-Cov2 coronas guaranteed to humanity a better survival. How many diabetic people who died in Italy, Spain, or the United States would be giving birth to diabetic people in the near future? How many people with cancer who died from Covid-19 should pass their risk factors on to their future offspring? How many young girls are reportedly avoiding marriage or a job offer because they have to care for their sick or elderly parent? How many young people will be spared the staggering costs of medical care for their parents, children or loved ones taken away by the Covid-19? These are all questions that can lead us to apply the cognitive resilience approach to the Covid-19 pandemic, an approach that requires focusing on the smallest positive dimensions of a catastrophic situation. Some may say that the parents took care of their children, so that the children also take care of them in the long run. Note that this conception of things is not natural. How many species in nature do we find such attitudes? Not even one to our knowledge. The young lion confronts and excludes his father from the troop when he loses his strength, without suspecting that it was he who defended him when he was vulnerable. The mother hen is ready to sacrifice her life for her chick, but does not expect anything from it when it becomes an adult. An evolutionary law of a humanist nature would be to give to his descendants, without expecting anything in return. The fact that those who survived Covid-19 will breed tomorrow, guarantees that humanity will no longer be shocked if this disease were to return. The American approach seems much closer to an evolutionary attitude, in that they refuse confinement, which would kill the economy of the country, which would disadvantage young people who are more spared from the pandemic. For them, we must let the pandemic take the elders, improving the economy of the nation, which guarantees the future of the youngest.

\section{Conclusion}

It emerges from this theoretical reflection on the passage of Covid-19 which has shaken the whole world since the beginning of 2020 that, this pandemic is a fatal reality, when it is considered in the present, but guarantees in the distant future, the survival 
of the 'human race. This survival is justified by the perpetuation by reproduction of able survivors, capable of transmitting genes beneficial to their descendants. In a world where the elderly have taken control, to the detriment of the more energetic and enduring young people, the Covid-19 will certainly give young people more opportunity, opportunities that they would not have had if the Covid-19 did not hadn't said his word. This reflection also shows, the limits of the conventional medical approach in the management of epidemics in general, and infectious diseases in particular: exorbitant expenses, mutations and development of resistance in bacteria and viruses under the effect of antibiotics, the inhibitory position vis-à-vis the defense mechanisms developed by the organism, and the propagation of the fear of parasites within human populations whereas these parasites are mostly beneficial for humans. We recommend here, the optimization of the defense mechanisms set up by the organism itself, because, contrary to human thought which is oriented by effective sensations and more or less divided perceptions of situations and phenomena, thought and the biological processes go beyond the analysis of effective stimulations, by integrating globally the sublimal processes in the establishment of the defense mechanisms which it sets up. In other words, conventional medicine isolates a disorder before taking care of it, while the organism takes into account all organismic processes before setting up a defense mechanism, which makes its approach more effective. Today's medicine would benefit from "respecting" the symptoms, as advocated by evolutionary medicine.

\section{Conflict of Interest}

No conflict of interest.

\section{Bibliography}

1. INSERN. "Coronavirus et Covid-19: Du simple rhume au syndrome respiratoire aigu sévère”. Répéré sur inserm.fr (2020).

2. Santé magazine. "Comment faire face au coronavirus covid-19?” Répéré sur www.santemagazine.fr (2020).

3. Workman L and Reader W. "Psychologie évolutionniste, une introduction". Bruxelles, De Boeck (2007).

4. Clamp A. "Evolutionary psychology". London: Hodder Headline (2001).

5. Quevauvilliers J., et al. "Dictionnaire médicale de poche". Paris: Masson (2009).
6. Kern J. "Covid-19: après la disparition des symptômes, certains malades sont toujours infectés". Répéré sur www.futurasciences.com (2020).

7. https://www.futura-sciences.com/sante/actualites/coronavirus-sars-cov-2-serait-melange-coronavirus-pangolinchauve-souris-79290/

8. Veyrie N. "Covid-19: l'obésité, un facteur de risque pour $20 \%$ des cas". Répéré sur doctisimo.fr le (2020).

9. Radio France Internationale. "Le coronavirus peut provoquer cette étrange sensation chez les personnes contaminées: la perte totale de goût et d'odorat. Les médecins français ont remarqué ce symptôme il y a une quinzaine de jours. Un symptôme massif notamment chez les jeunes adultes". Répéré sur rfi.fr les (2020).

10. Godefroid J. "Psychologie, science humaine et cognitive". Bruxelles, De Boeck University (2011).

11. Flutre T., et al. "La théorie de la sélection naturelle présentée par Darwin et Wallace". Bibnum [En ligne], Sciences de la vie, mis en ligne le 01 décembre 2009, répéré sur journals. openedition.org (2020).

12. Karen J. "Symptômes du covid-19: les patients sont contagieux entre 8 et 37 jours". Répéré sur futura-sciences.com (2020).

13. Karen J. "Symptômes du covid-19: le diabète et l'hypertension comme facteurs aggravants". Répéré sur futura-sciences.com (2020).

\section{Assets from publication with us}

- Prompt Acknowledgement after receiving the article

- Thorough Double blinded peer review

- Rapid Publication

- Issue of Publication Certificate

- High visibility of your Published work

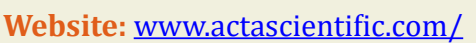

Submit Article: www.actascientific.com/submission.php

Email us: editor@actascientific.com

Contact us: +919182824667 